\title{
Standard elevation models for evaluating terrain representation
}

\author{
Patrick Kennelly ${ }^{\mathrm{a}}{ }^{*}$, Tom Patterson ${ }^{\mathrm{b}}$, Alexander Tait ${ }^{\mathrm{c}}$, Bernhard Jenny ${ }^{\mathrm{d}}$, Daniel Huffman ${ }^{\mathrm{e}}$, Sarah \\ Bell $^{\mathrm{f}}$, Brooke Marston ${ }^{\mathrm{g}}$ \\ ${ }^{a}$ Long Island University, patrick.kennelly@liu.edu \\ ${ }^{b}$ US National Parks Service (Ret.),mtnmapper@gmail.com \\ ${ }^{c}$ National Geographic Society, atait@ngs.org \\ ${ }^{d}$ Monash University, bernie.jenny@monash.edu \\ ${ }^{e}$ somethingaboutmaps, daniel.p.huffman@gmail.com \\ ${ }^{f}$ Esri, sbell@esri.com \\ ${ }^{g}$ Brooke Marston, marston.brooke@gmail.com \\ * Corresponding author
}

Keywords: Terrain representation, digital elevation model, relief shading, standard data models

\section{Standard Elevation Models}

We propose the use of standard elevation models to evaluate and compare the quality of various relief shading and other terrain rendering techniques. These datasets will cover various landforms, be available at no cost to the user, and be free of common data imperfections such as missing data values, resampling artifacts, and seams. Datasets will be available at multiple map scales over the same geographic area for multi-scale analysis.

Utilizing a standard data model for testing and comparing methods is a common practice among many disciplines. Furthermore, the use of digital models to test rendering techniques based on qualitative visual production has been well established for decades. Following the generation of the first digital image in 1957, image processing and analysis required standard test images upon which methods could be tested and compared. During the 1960s and 1970s, many well-known standard test images emerged from this need for a comparative technique model. Today, institutions like the University of Southern California's Signal and Image Processing Institute maintain digital image databases for the primary purpose of supporting image processing and analysis research, including geographic imaging processes.

Several well-known test models have also emerged from the world of three-dimensional image analysis. 3D test models like Newell's Utah teapot, for example, is a dataset created for testing computer generated rendering techniques like shading and textures (Lehman, 173-174). Although the Utah teapot differs slightly from its real life Melitta subject, it is derived from a real and recognizable object characterized by various topological features upon which rendering algorithms can be tested. Much like the free and open Utah teapot dataset, our spatial elevation test models are free of data imperfections for the purposes of surficial rendering methods testing. However, while the Utah teapot is a single model, ours is a series of test models at various geographic scales.

While the need for standard digital test images began to emerge in computer graphics, the use of sensors mounted on airplanes and satellites to collect voluminous data began to thrive, producing new datasets that required novel processing and evaluation methods. High-resolution digital elevation models capturing detailed slope, elevation, and other topographic attributes, now offer earth scientists and cartographers powerful digital datasets for both understanding and rendering Earth's landscape. Among the branches of geo-science benefitting from high-resolution digital elevation models (DEM) was geomorphometry.

Geomorphometry and relief shading techniques overlap in many aspects in that they are both areas of geographic rendering that make use of digital elevation models and other similar datasets for cartographic representation (Pike et al. 2009). Both branches of topographical representation pre-date computerized mapping, yet have been revolutionized with the growth of computer processing, thus routinizing their implementations (Pike 1999). However, since geomorphometric applications parameterize complex geomorphological influences for quantitative topographical analysis, many differences exist between geomorphometric models, such as predictive vegetation modeling and our proposed standard elevation models. Although our standard elevation models are created for testing mapping techniques, unlike geomorphometric models, ours are not for predicting or identifying landscape or geomorphological occurrences. Rather, the standard elevation models we propose are for the evaluation of cartographic rendering itself.

Many studies to date have evaluated methods to render terrain for display for both two- and three-dimensional (2D and 3D) cartographic displays. In general, the evaluation involves comparing the new rendering with well-known and 
sometimes hand-rendered exemplars or typical terrain rendering techniques. Examples of the former include methods to reproduce historical Swiss-stlye rock drawings (Jenny et al., 2014), hand-drawn relief shading (Bell, 2018), and create plan oblique relief effects (Jenny and Patterson 2007), while examples of the latter include many examples that compare custom relief shading techniques with default hillshading techniques found in typical geographic information system (GIS) software (e.g. Huffman 2019, Marston and Jenny 2015, Kennelly and Stewart 2014, Tait 2002, Patterson 1997). Such studies typically involve searching for an appropriate and high quality DEM dataset, tasks that could be simplified with standard elevation models.

Additionally, past research provides us with an opportunity to inventory the DEM data that was used previously in an effort to better understand the characteristics of the study areas that were selected. We will look at these past studies to determine attributes such as the geographic location, extent, and scale of previous models used to evaluate terrain representations. We will begin with reviews of relief shading and hypsometric tinting studies, and may expand our analysis to include other techniques such as 3D terrain mapping or other specialized techniques such as hachuring.

While the idea of what a standard elevation model for relief shading is may evolve as the study progresses, we currently plan to focus on the following ideas in searching for candidates. As previously stated, the data should be free to distribute, of high quality, cover various landforms and be available at multiple scales. The standard elevation models should also cover areas that have been mapped frequently over time. Historical and contemporary geo-referenced terrain maps should be available for these areas to allow the user to easily compare new techniques to existing cartographic products. We hope that developers of new algorithms will use the standard elevation models to compare their results to previously existing methods and maps.

\section{References}

Bell, S. 2018. Drawing Hillshade: A tutorial (with time lapse videos). http://bit.ly/drawinghillshade

Franklin, J., 1995. Predictive vegetation mapping: geographic modelling of biospatial patterns in relation to environmental gradients. Progress in physical geography, 19(4), pp.474-499.

Huffman, D. 2019. Creating shaded relief in Blender https://somethingaboutmaps.wordpress.com/2017/11/16/creatingshaded-relief-in-blender/

Jenny, B., Gilgen, J., Geisthövel, R., Marston, B.E. and Hurni, L., 2014. Design principles for Swiss-style rock drawing. The Cartographic Journal, 51(4), pp.360-371.

Jenny, B. and Patterson, T., 2007. Introducing plan oblique relief. Cartographic Perspectives, (57), pp.21-40.

Kennelly, P.J. and Stewart, A.J., 2014. General sky models for illuminating terrains. International Journal of Geographical Information Science, 28(2), pp.383-406.

Lehmann, A.S., 2012. Taking the Lid off the Utah Teapot Towards a Material Analysis of Computer Graphics. Zeitschrift für Medien-und Kulturforschung, 2012(1), pp.169-184.

Marston, B.E. and Jenny, B., 2015. Improving the representation of major landforms in analytical relief shading. International Journal of Geographical Information Science, 29(7), pp.1144-1165.

Patterson, T., 1997. A desktop approach to shaded relief production. Cartographic Perspectives, (28), pp.38-39.

Pike, R.J., 2002. A bibliography of terrain modeling (geomorphometry), the quantitative representation of topography. USGS Open file report, pp.02-465. US Department of the Interior, US Geological Survey.

Pike, R.J., 1999. A bibliography of geomorphometry, the quantitative representation of topography: Supplement 3.0. USGS Open file report 96-726. US Department of the Interior, US Geological Survey.

Pike, R.J., Evans, I.S. and Hengl, T., 2009. Geomorphometry: a brief guide. Developments in Soil Science, 33, pp.3-30.

Tait, A., 2002. Photoshop 6 tutorial: How to create basic colored shaded relief. Cartographic Perspectives, (42), pp.1217. 